Revista Chilena
De Pediatría

www.revistachilenadepediatria.cl

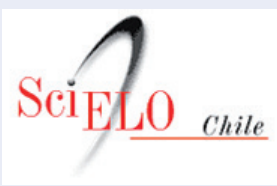

www.scielo.cl

\title{
La Publicación Científica en tiempos de COVID-19
}

\section{Scientific publication in the time of COVID-19}

\author{
Luisa Schonhaut B. ${ }^{\text {a }}$, Paul R. Harris ${ }^{\text {a }}$, Francisco Cano Sch. ${ }^{\mathrm{a}}$
}

${ }^{a}$ Comité Editorial Revista Chilena de Pediatría, Sociedad Chilena de Pediatría, Chile

Con la llegada del SARS-CoV-2 y sus dramáticos efectos en la población, se han generado cambios que han afectado todos los aspectos de la vida, desde lo más doméstico e individual hasta remecer las bases de la sociedad en sus estructuras y funcionamientos sanitarios y económicos. El mundo entero en forma casi simultánea está enfrentando un virus desconocido con un comportamiento impredecible, por lo CUAL distintos centros, hospitales, universidades, sociedades científicas y grupos de especialistas han elaborado guías de manejo, cuyo impacto es aún desconocido, pero han servido para disminuir la variabilidad y uniformar las conductas, lo que se asocia a una sensación de "seguridad".

En el área de las publicaciones científicas, esta pandemia ha condicionado una necesidad urgente de adquirir y difundir conocimiento que rápidamente pueda llegar a todos los especialistas y que pueda contribuir a mejorar aspectos preventivos y terapéuticos.

A pesar del antiguo conocimiento de los coronavirus desde la década de los 60 , y con más de 24.000 publicaciones en Medline bajo la palabra clave "coronavirus", este nuevo COVID-19 parece revestir una capacidad patogénica y transmisibilidad no vista previamente en sus antecesores, SARS-CoV (severe acute respiratory syndrome) y MERS (Middle East respiratory syndrome). La búsqueda en Pubmed del término COVID-19, con fecha 24 de mayo de 2020, arroja 15.673 documentos (62\% de las publicaciones sobre coronavirus) tan sólo para el año en curso; de estos,
10.516 son manuscritos publicados en revistas científicas, con 11 ensayos clínicos y 18 metaanálisis (https:// pubmed.ncbi.nlm.nih.gov/?term=covid+19\&filter=ye ars.2020-2020).

Para hacernos una noción de lo apresurado que ha sido el proceso de generación de conocimiento y publicaciones en medio de la Pandemia, podemos analizar los tiempos habituales de publicación para manuscritos del área médica. Los procesos de revisión por pares demoran en promedio 12 semanas por ronda de revisión $^{1}$, con un tiempo total desde el envío del manuscrito a su aceptación, por lo general, mayor a 4 meses $^{2}$. Por otro lado, debemos considerar cuánto tarda un investigador en realizar su estudio; en el caso de revisiones sistemáticas, el tiempo estimado para que un protocolo sea completado y publicado es de 15 meses $^{3}$. En la tabla y figura 1 se ilustran los tiempos editoriales, basada en los últimos manuscritos publicados en PubMed sobre COVID-19 en niños, tomando como comparación las publicaciones sobre influenza en la infancia; destaca que para COVID-19 el tiempo editorial total fue de 16 días (rango 1 a 37), comparando con 179 días para los manuscritos de influenza (rango 66 a 356). No es de extrañar entonces que a la fecha ya existan 7 manuscritos de COVID retirados o retractados, comparado con sólo 1 de influenza retirado.

En esta urgencia por publicar, sin duda, se ha sacrificado "calidad" por "necesidad", con una cuota de "oportunidad". Existe sobretodo "necesidad" de compartir guías de prevención y manejo, las que se han

Correspondencia:

Luisa Schonhaut B.

Ischonhaut@alemana.cl 
Tabla 1. Tiempos editoriales para los últimos manuscritos publicados en Pubmed sobre COVID-19 vs influenza

\begin{tabular}{lccc}
\hline Manuscritos & COVID-19 (promedio y rango) & Influenza (promedio y rango) & p value \\
\hline $\mathrm{N}$ & 22 & 21 & $<0,000$ \\
Tiempo de revisión (días) & $5,7(1-23)$ & $148(61-293)$ & 0,005 \\
Tiempo de publicación (días) & $10,6(1-27)$ & $29,9(1-113)$ & $<0,000$ \\
Tiempo editorial total (días) & $16,3(1-37)$ & $178,8(66-356)$ & \\
\hline
\end{tabular}

Tiempo revisión: Tiempo desde que el manuscrito es recibido hasta que es aceptado. Tiempo publicación: Tiempo desde que el manuscrito es aceptado a publicado. Tiempo editorial total: Tiempo total desde que el manuscrito es recibido hasta su publicación.

Análisis en base a los últimos 40 manuscritos publicados en Pubmed que contenían los siguientes criterios de inclusión: área temática COVID-19

o influenza en población pediátrica, de acceso abierto y publicados en idioma inglés, que contenían información de los tiempos de publicación.

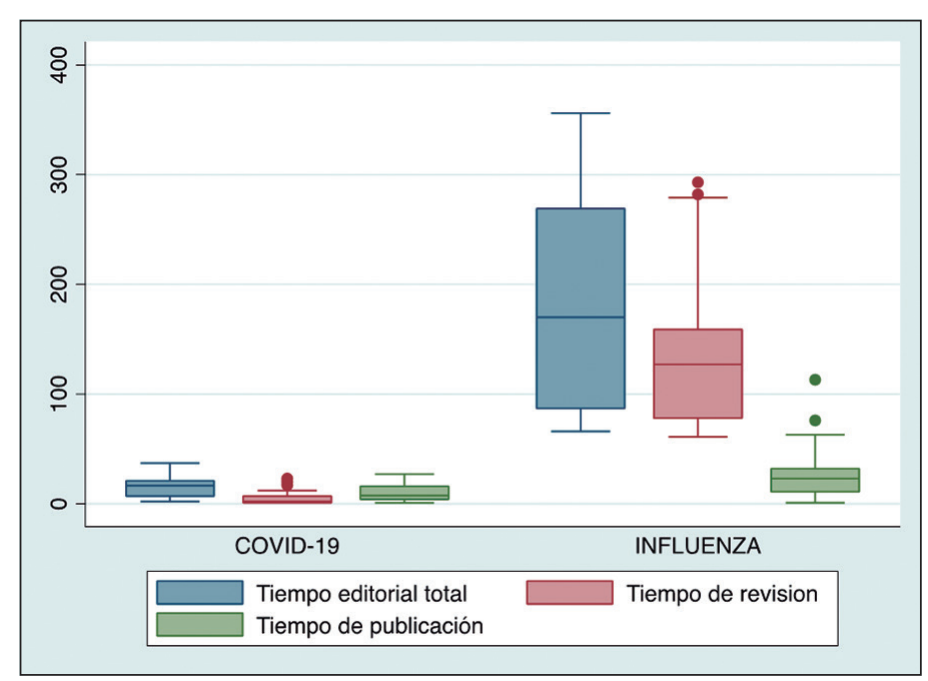

Figura 1. Tiempos del proceso editorial desde que el manuscrito es recibido, aceptado y publicado. Tiempo revisión: Tiempo desde que el manuscrito es recibido hasta que es aceptado. Tiempo publicación: Tiempo desde que el manuscrito es aceptado a publicado. Tiempo editorial total: Tiempo total desde que el manuscrito es recibido hasta su publicación. Análisis en base a los últimos 40 manuscritos publicados en Pubmed que contenían los siguientes criterios de inclusión: área temática COVID-19 o influenza en población pediátrica, de acceso abierto y publicados en idioma inglés, que contenían información de los tiempos de publicación.

basado más en la experiencia clínica que en la evidencia científica. Dichas normas se han ido actualizando constantemente, quedando obsoletas tras un breve periodo, identificándose, a la fecha 589 guías clínicas relacionadas con COVID-19 en PubMed. El simple hecho de que Bases de Datos y Librerías Digitales como ScIELO hayan abierto espacio para que los autores suban sus manuscritos en forma preliminar sin pasar por revisión por pares (https://preprints.scielo.org/index. $\mathrm{php} / \mathrm{scielo}$ ), habla de la urgencia en comunicar toda experiencia que pueda ser útil para enfrentar una amenaza de características patogénicas y comportamiento desconocido. En los últimos años, otras plataformas se han sumado a la publicación de manuscritos previo a evaluación por pares, dado lo lento y dificultoso de un proceso en que los revisores en general no obtienen retribución ni académica ni económica, como arXiv, medRxiv and bioRxiv, bajo el encabezado de "see COVID-19 SARS-CoV-2 preprints".

Conscientes de que mucho de lo publicado no necesariamente cumple con el rigor de una publicación científica en tiempos normales, pero al mismo tiempo asumiendo una necesidad de difusión activa y oportuna, es que el Comité Editorial de Revista Chilena de Pediatría (RChP) ha decidido publicar un Número Especial que reúne Recomendaciones y Guías provenientes de diversas Sociedades científicas.

En primer lugar, se incluyen GUÍAS CLINICAS elaboradas por las Ramas y Comités de expertos de la Sociedad Chilena de Pediatría (SOCHIPE). Muchas de ellas se basan en documentos internacionales recientemente publicados o difundidos por medios menos tradicionales de RRSS. En segundo lugar, se incluyen links a sitios webs de GUÍAS INTERNACIONALES validadas y publicados por sociedades científicas de Europa y Norteamérica. El acceso a dicho sitios permitirá al lector una lectura inmediata del material original sin ninguna modificación o adaptación a la realidad chilena. En tercer lugar, se incluyen artículos originales de revisión de temas relacionados a la pandemia y realizados en breve tiempos por especialistas nacionales. Finalmente, es los próximos números regulares de la Revista, podremos ver manuscritos originales, que, habiendo sido revisados por pares, han sido aceptados para su publicación por su calidad y/o importancia.

Esperamos que estas 4 instancias puedan contribuir a que los lectores de RCHP puedan acceder a material relevante en forma oportuna. Estamos conscientes de que parte de este material es heterogéneo en calidad y cuya validez por definición es transitoria y cambiante, en un escenario donde el conocimiento sobre este nuevo agente viral es sumado día a día por la comunidad científica.

\section{Conflicto de interés}

Los autores declaran no tener conflicto de intereses. 


\section{Referencias}

1. Huisman J, Smits J. Duration and quality of the peer review process: the author's perspective. Scientometrics 2017;113:63350.

2. Sabaj O, Valderrama JO, González-
Vergara C, Pina-Stranger Á. Relationship between the duration of peer review, publication decision, and agreement among reviewers in three Chilean journals. European Science Editing. 2015;41(4): 87-90.
3. Borah R, Brown AW, Capers PL, Kaiser KA. Analysis of the time and workers needed to conduct systematic reviews of medical interventions using data from the PROSPERO registry. BMJ open. 2017;7(2):e012545. 